\title{
Identification and validation of FGFR2 peptide for detection of early Barrett's neoplasia
}

\author{
Juan Zhou ${ }^{1}$, Lei He${ }^{2}$, Zhijun Pang², Henry D. Appelman³, Rork Kuick ${ }^{4}$, David G. \\ Beer ${ }^{5}$, Meng $\mathbf{L i}^{2}$ and Thomas D. Wang ${ }^{1,6,7}$ \\ ${ }^{1}$ Department of Medicine, Division of Gastroenterology, University of Michigan, Ann Arbor, Michigan 48109, USA \\ ${ }^{2}$ Biotechnology Center, School of Pharmacy, The Fourth Military Medical University, Xi'an 710032, China \\ ${ }^{3}$ Department of Pathology, University of Michigan, Ann Arbor, Michigan 48109, USA \\ ${ }^{4}$ Department of Biostatistics, University of Michigan, Ann Arbor, Michigan 48109, USA \\ ${ }^{5}$ Department of Surgery, Section of Thoracic Surgery, University of Michigan, Ann Arbor, Michigan 48109, USA \\ ${ }^{6}$ Department of Biomedical Engineering, University of Michigan, Ann Arbor, Michigan 48109, USA \\ ${ }^{7}$ Department of Mechanical Engineering, University of Michigan, Ann Arbor, Michigan 48109, USA \\ Correspondence to: Meng Li, email: lemon781106@hotmail.com \\ Thomas D. Wang, email: thomaswa@umich.edu \\ Keywords: FGFR2, peptide, esophagus, cancer \\ Received: May 26, $2017 \quad$ Accepted: July 03, $2017 \quad$ Published: August 01, 2017 \\ Copyright: Zhou et al. This is an open-access article distributed under the terms of the Creative Commons Attribution License 3.0 \\ (CC BY 3.0), which permits unrestricted use, distribution, and reproduction in any medium, provided the original author and source \\ are credited.
}

\section{ABSTRACT}

The incidence of esophageal adenocarcinoma (EAC) is rising rapidly, and early detection within the precursor state of Barrett's esophagus (BE) is challenged by flat premalignant lesions that are difficult detect with conventional endoscopic surveillance. Overexpression of cell surface fibroblast growth factor receptor 2 (FGFR2) is an early event in progression of BE to EAC, and is a promising imaging target. We used phage display to identify the peptide SRRPASFRTARE that binds specifically to the extracellular domain of FGFR2. We labeled this peptide with a nearinfrared fluorophore Cy5.5, and validated the specific binding to FGFR2 overexpressed in cells in vitro. We found high affinity $k_{d}=68 \mathrm{nM}$ and rapid binding $k=0.16 \mathrm{~min}^{-1}(6.2$ min). In human esophageal specimens, we found significantly greater peptide binding to high-grade dysplasia (HGD) versus either BE or normal squamous epithelium, and good correlation with anti-FGFR2 antibody. We also observed significantly greater peptide binding to excised specimens of esophageal squamous cell carcinoma and gastric cancer compared to normal mucosa. These results demonstrate potential for this FGFR2 peptide to be used as a clinical imaging agent to guide tissue biopsy and improve methods for early detection of EAC and potentially other epithelial-derived cancers.

\section{INTRODUCTION}

There are over 450,000 new cases of esophageal cancer diagnosed worldwide each year, resulting in more than 400,000 deaths annually [1]. Esophageal adenocarcinoma (EAC) represents the majority of cases in the U.S., where the incidence and mortality continue to rise rapidly [2]. This trend is attributed to increasing obesity and chronic gastroesophageal reflux disease (GERD) [3]. Barrett's esophagus (BE) is the replacement of normal squamous epithelium with intestinal metaplasia, and can transform into low-grade dysplasia (LGD) and progress to high-grade dysplasia (HGD) prior to developing EAC [4]. LGD represents increased risk, but pathological diagnosis of this condition can be subjective and inconsistent in interpretation [5]. Conventional white 
light endoscopy with random four-quadrant tissue biopsies has been recommended for surveillance of BE patients [6]. Therapy includes endoscopic mucosal resection (EMR), radio-frequency ablation (RFA), and surgery for improved patient outcomes [6]. Unfortunately, endoscopic strategies for detection of pre-malignant lesions are limited by sampling error, flat architecture, and patchy distribution [7]. Molecular changes associated with gene alterations precede histopathological abnormalities, and may be developed for imaging as an adjunct to endoscopy for early cancer detection [8].

Receptor tyrosine kinases (RTKs) are expressed on the cell membrane, where they are accessible for in vivo imaging [9]. They occupy key regulation points for cell signaling during cancer progression. FGFR2 has been found to be highly expressed early in progression from $\mathrm{BE}$ to EAC [10]. FGFR2 is a member of the fibroblast growth factor receptor (FGFR) family that includes FGFR1-4, [11] which are glycoproteins located on the cell surface, and consist of 3 extracellular immunoglobulin (Ig)-like domains, a hydrophobic transmembrane region, and a cytoplasmic domain that contains a tyrosine kinase catalytic domain [12]. More than 20 alternative splicing variants of FGFR2 have been identified [13]. Major splicing occurs in the carboxyl terminus of the third Ig-like domain (D3). Isoform IIIb or IIIc of FGFR2 is generated when the C-terminus of D3 is encoded by either exon 8 or 9, respectively. FGF-1, 3, 7, 10, and 22 are known to bind to FGFR2b, while FGF-1, 2, 4, 6, 9, 17, and 18 bind to FGFR2c. Binding of FGF to FGFR2 phosphorylates specific tyrosine residues that mediate interactions with cytosolic adaptor proteins and activates intracellular signaling cascades, such as RAS-MAPK, PI3K-AKT, PLC $\gamma$, and STAT [14-18].

Use of peptides to detect and localize Barrett's neoplasia with imaging has recently been demonstrated in the clinic $[19,20]$. An empiric peptide labeled with FITC was administered topically to the mucosal surface. Early neoplasia was detected with $94 \%$ specificity and $96 \%$ positive predictive value. Included in the analysis were 28 flat lesions (Paris 0-IIb) that were poorly visualized with white light. Binding occurred within $5 \mathrm{~min}$, which resulted in minimal time added to the diagnostic procedure. Peptides have high diversity, and can achieve high specificity with binding affinities on the nanomolar scale. This probe platform has flexibility to be labeled with a broad range of fluorophores, [21] and is inexpensive to produce in large quantities. These features of peptides are well suited for clinical use in high volume procedures. Barrett's metaplasia involves only a few centimeters of the distal esophagus, thus topical peptide administration can achieve high concentrations to maximize target interactions and achieve rapid binding with minimal risk for toxicity [22]. The quantity, hence cost, of the imaging agent needed is minimized, and probe biodistribution to non-target tissues is avoided for increased safety. Here, we aim to develop a novel peptide that targets FGFR2, and demonstrate specific binding to Barrett's neoplasia. In the future, this peptide can be used clinically for early cancer detection, image-guided resection, risk stratification, and monitoring of therapeutic efficacy.

\section{RESULTS}

\section{Selection of peptide specific for FGFR2}

We performed immunohistochemistry (IHC) on specimens of human esophagus, including squamous (SQ), Barrett's esophagus (BE), low-grade dysplasia (LGD), high-grade dysplasia (HGD), and esophageal adenocarcinoma (EAC), that were classified by an expert gastrointestinal pathologist (HDA) to demonstrate representative levels of FGFR2 expression, Supplementary Figure 1. The extra-cellular domain (ECD) of FGFR2 consists of a signal peptide (SP) and 3 extracellular immunoglobulin-like domains (D1-D3), Supplementary Figure 2A. We used FGFR2-ECD with purity $>97 \%$ by HPLC. SDS-PAGE shows apparent molecular mass of $\sim 65-75 \mathrm{kDa}$, Supplementary Figure 2B. This result is slightly higher than the expected value of $41 \mathrm{kDa}$ as a result of glycosylation of the FGFR2 protein. After 4 rounds of biopanning with phage display, we found 2 sequences that showed enrichment. In 50 clones, SRRPASFRTARE appeared 15X and GLHTSATNLYLH appeared 4X. GLHTSATNLYLH was found previously when we biopanned against other protein targets, and is likely an unrelated sequence.

\section{Peptide specific for FGFR2}

We synthesized the 12 amino acid sequence SRRPASFRTARE (black) and attached the fluorophore Cy5.5 (red) via a GGGSK linker (blue) on the C-terminus, hereafter SRR*-Cy5.5, Figure 1A. Cy5.5 was chosen for photostability and high quantum yield in the nearinfrared (NIR) spectrum [23]. We used a linker to prevent steric hindrance of the peptide by the dye. We then used a structural model (1EV2), [24] Figure 1B, and found SRR ${ }^{*}-$ Cy5.5 to bind to domains D2 and first half of D3 of FGFR2- ECD with a total energy $E_{t}=-290.43$. This domain is the same in either isoform FGFR2IIIb or FGFR2IIIc. We also used this model to develop a scrambled sequence SPSRERTFRARA for a control, Figure 1C. This peptide was also labeled with Cy5.5 via a GGGSK linker, hereafter SPS ${ }^{*}-\mathrm{Cy} 5.5$. For SPS*-Cy5.5, we calculated $E_{t}=-277.37$. The fluorescence spectra of SRR $^{*}$-Cy5.5 and SPS ${ }^{*}$-Cy5.5 with $\lambda_{\text {ex }}=671 \mathrm{~nm}$ excitation revealed a peak emission at $\lambda_{\mathrm{em}}=710 \mathrm{~nm}$, Figure 1D. We purified SRR ${ }^{*}-$ Cy5.5 and SRS ${ }^{*}-C y 5.5$ to $>97 \%$ on HPLC, and measured an experimental mass-to-charge $(\mathrm{m} / \mathrm{z})$ ratio on mass spectrometry of 2385.31 for both peptides that agreed with the expected value, Supplementary Figure 3. 


\section{Confocal fluorescence microscopy}

On confocal microscopy, we validated specific peptide binding to human immortalized $\mathrm{BE}$ cells that express FGFR2. We observed strong signal with SRR*Cy5.5 on the surface of QhTERT cells that express either FGFR2b or FGFR2c and minimal signal for wild-type, Figure 2A-2C. Minimal binding was observed for the scrambled control peptide SPS ${ }^{*}$ Cy5.5 with all cells, Figure 2D-2F. We confirmed these findings using antiFGFR2 antibody labeled with AF488, Figure 2G-2I. We quantified our results, and found a significantly greater mean fluorescence intensity for SRR ${ }^{*}$-Cy5.5 than for control with QhTERT cells that express either FGFR2b or FGFR2c compared with wild-type, Figure 2J. Western blot shows of FGFR2 expression level for each cell, Figure 2K.

\section{Competition for peptide binding}

We administered unlabeled SRR*, and used confocal microscopy to observe competition for binding of SRR ${ }^{*}$ Cy5.5 to QhTERT cells that express FGFR2c, Figure $3 \mathrm{~A}-3 \mathrm{~L}$. We quantified the mean fluorescence intensities, and observed a significant reduction at concentrations of $50 \mu \mathrm{M}$ and greater of SRR ${ }^{*}$ compared with that at 0 $\mu \mathrm{M}$, Figure $3 \mathrm{M}$. No significant difference was found with addition of unlabeled control SPS ${ }^{*}$ at any concentration. This result supports binding of the peptide rather than the fluorophore to FGFR2.

\section{Characterization of peptide binding}

Using flow cytometry, we measured an apparent dissociation constant of $\mathrm{k}_{\mathrm{d}}=68 \mathrm{nM}$ for binding of SRR*Cy5.5 to QhTERT cells that express FGFR2c, Figure 3N. This result provides an estimate for binding affinity. We also measured an apparent association time constant of $\mathrm{k}$ $=0.16 \mathrm{~min}^{-1}$ for binding of SRR ${ }^{*}$-Cy5.5 to QhTERT cells that express FGFR2c, Figure 3O. This result provides time scale of $\sim 6.2 \mathrm{~min}$ for onset of binding.

\section{Binding of FGFR2 peptide and antibody to human esophageal neoplasia}

On confocal microscopy, we evaluated staining of the FGFR2 peptide SRR ${ }^{*}$-Cy5.5 to sections of human esophagus ex vivo. We observed minimal fluorescence intensity with squamous (SQ) and BE, Figure 4A, 4B, and strong signal with HGD and EAC, Figure 4C, 4D. We confirmed these results with AF488-labeled anti-FGFR2 antibody, Figure 4E-4H. Fluorescence intensities were measured from a set of 3 boxes with dimensions of $30 \times 30$ $\mu \mathrm{m}^{2}$ to calculate the target-to-background (T/B) ratio. The mean ( \pm std) T/B ratio for SRR ${ }^{*}$-Cy5.5 was significantly higher for HGD and EAC than that for BE and SQ, Figure 4I. These results are consistent with that with anti-FGFR2 antibody, Figure 4J. From the ROC curve, we found $87 \%$ sensitivity and $70 \%$ specificity for this peptide to detect Barrett's neoplasia (HGD and EAC) at a T/B ratio of 3.0

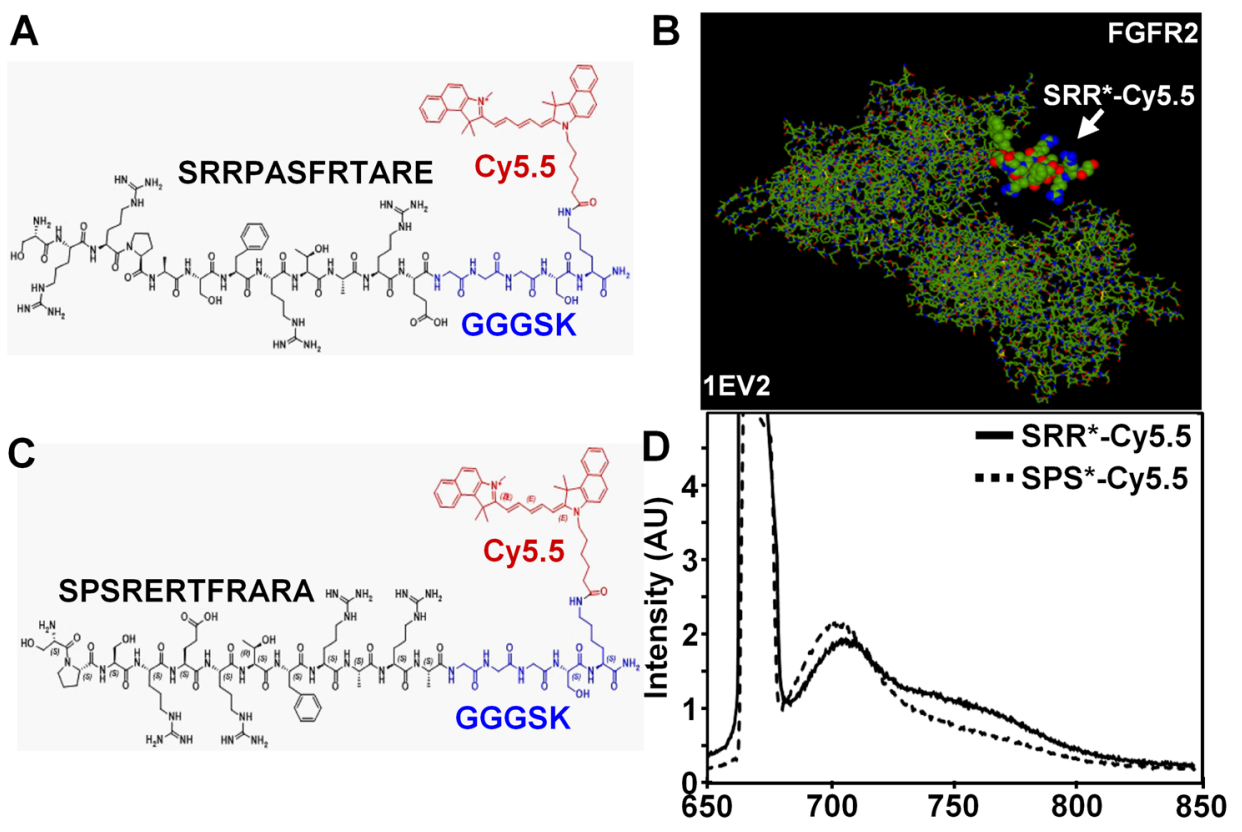

Figure 1: Peptide specific for FGFR2. Chemical structure is shown for 12 amino acid (aa) peptide sequence (A) SRRPASFRTARE $\left(\mathrm{SRR}^{*}\right.$ ) found to be specific for FGFR2, and (B) scrambled peptide SPSRERTFRARA (SPS*) used for control. A Cy5.5 fluorophore (red) is attached via a GGGSK linker (blue) to prevent steric hindrance. (C) SRR ${ }^{*}$-Cy5.5 was found using a structural model (1EV2) to bind to the extracellular domain (ECD) of FGFR2c (147-366 aa) with $E_{t}=-290.43$ while SPS ${ }^{*}$-Cy5.5 resulted in $E_{t}=-277.37$. (D) Fluorescence spectra of SRR ${ }^{*}$-Cy5.5 and SPS ${ }^{*}$-Cy5.5 at $10 \mu \mathrm{M}$ concentration in PBS with excitation at $\lambda_{\mathrm{ex}}=671 \mathrm{~nm}$ shows peak emission at $\lambda_{\text {em }}=710$ $\mathrm{nm}$ in the NIR spectrum. 
when compared with pathology, Figure $4 \mathrm{~K}$. We plot the fluorescence intensities for all specimens, and found good correlation between SRR ${ }^{*}$-Cy5.5 and anti-FGFR2-AF488 with $\mathrm{R}=0.66$, Supplementary Figure 4. Co-localization of peptide and antibody binding can be seen on merged images, Figure 4K-4N. Corresponding histology (H\&E) were shown in Figure 4O-4R.

\section{Effect of FGFR2 peptide binding on cell signaling}

We evaluate the effect of peptide binding on downstream signaling in QhTERT cells that express either FGFR2b or FGFR2c. Western blot shows no change in phosphorylation of either FGFR2 (p-FGFR) or downstream AKT (p-AKT) and ERK (p-ERK) with addition of SRR* peptide at a concentration of either 5 or $100 \mu \mathrm{M}$, Figure $5 \mathrm{~A}$. By comparison, we observed strong phosphorylation activity of FGFR2 (p-FGFR), downstream AKT (p-AKT) and ERK (p-ERK) with addition of positive control FGF1 in QhTERT cells that express FGFR2c and to some extent or FGFR2b.

\section{Binding of FGFR2 peptide to human squamous cell and gastric cancer}

On confocal microscopy, we observed strong fluorescence intensity from incubation of the FGFR2 peptide SRR ${ }^{*}$-Cy5.5 to sections of human esophageal squamous cell cancer ( $\mathrm{SCC}$ ) ex vivo in $\mathrm{n}=35$ patients, Supplementary Figure 5A. We confirmed this result with AF488-labeled anti-FGFR2 antibody, Supplementary Figure 5B. We observed good co-localization of peptide and antibody binding on merged images, Supplementary Figure 5C. Representative histology (H\&E) for SCC is shown, Supplementary Figure 5D. By comparison, we observed minimal fluorescence intensity in normal human esophagus with either peptide or antibody, Supplementary Figure 5E-5G. Representative histology (H\&E) for normal stomach is shown, Supplementary Figure $5 \mathrm{H}$.

On confocal microscopy, we also observed strong fluorescence intensity from staining of the FGFR2 peptide SRR*-Cy5.5 to sections of human gastric cancer ex vivo in $\mathrm{n}=33$ patients, Supplementary Figure 6A. We confirmed this result with AF488-labeled anti-FGFR2 antibody, Supplementary Figure 6B. We

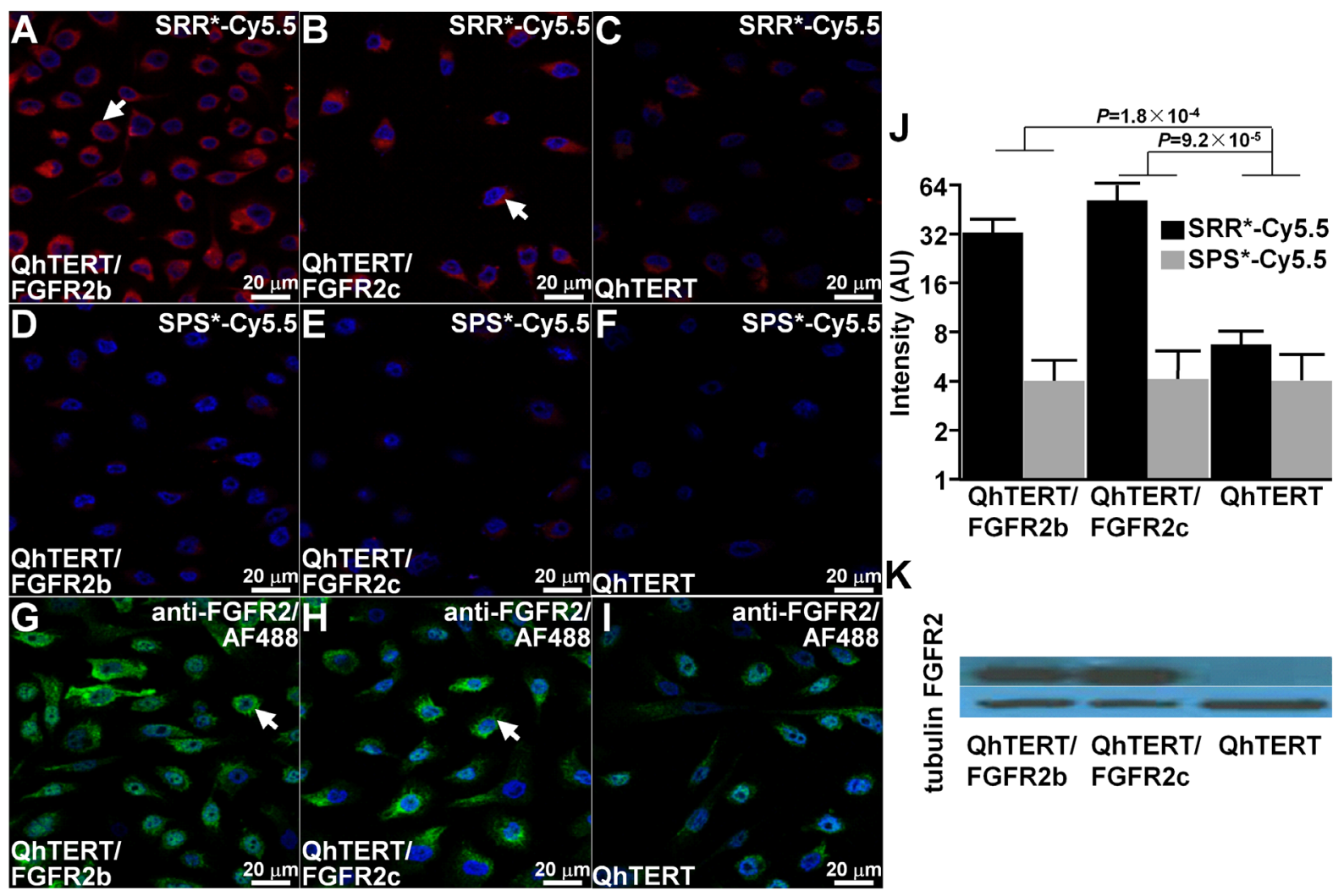

Figure 2: Validation of specific FGFR2 peptide binding to cells. On confocal microscopy, we observed strong binding of SRR*Cy5.5 (red) to surface of QhTERT cells that express (A) FGFR2b and (B) FGFR2c compared with (C) wild type. (D-F) Minimal signal is seen with the scrambled peptide SPS ${ }^{*}$-Cy5.5. (G-I) Strong binding is seen with anti-FGFR2 antibody labeled with AF488 (green) used as positive control. All experiments were performed in triplicate. (J) Quantified results show significantly higher mean fluorescence intensities for SRR ${ }^{*}$-Cy5.5 versus SPS*-Cy5.5 (control). We log-transformed and averaged measurements for 3 random cells on each of 3 slides per condition, and fit an ANOVA model with terms for 6 means. (K) Western blot shows protein expression level of FGFR2 for each cell. 
observed good co-localization of peptide and antibody binding on merged images, Supplementary Figure 6C. Representative histology (H\&E) for gastric cancer is shown, Supplementary Figure 6D. By comparison, we observed minimal fluorescence intensity in normal human stomach with either peptide or antibody, Supplementary Figure 6E-6G. Representative histology (H\&E) for normal stomach is shown, Supplementary Figure $6 \mathrm{H}$.

We quantified fluorescence intensities from a set of 3 boxes with dimensions of $30 \times 30 \mu \mathrm{m}^{2}$ in each image and found a significantly greater result for SCC versus normal and for gastric cancer versus normal, Supplementary Figure 6I, 6J, respectively.

\section{DISCUSSION}

Here, we have identified a novel peptide specific for FGFR2 that binds to the extra-cellular Ig-like domain of isoforms IIIb and IIIc. Expression of FGFR2 has been identified as an early event in progression from $\mathrm{BE}$ to EAC [10]. We demonstrate accessibility for imaging by showing that this peptide binds to the cell membrane in vitro, and confirm specificity for FGFR2 using siRNA knockdown and competition results. These studies were rigorously controlled using a scrambled peptide. We found this peptide to bind cells with high affinity of $\mathrm{k}_{\mathrm{d}}=$ $68 \mathrm{nM}$ and rapid binding onset of $\mathrm{k}=0.16 \mathrm{~min}^{-1}(6.2 \mathrm{~min})$. We labeled this peptide with Cy5.5, a NIR fluorophore, and visualized specific cell surface staining to neoplasia in human specimens of BE, SCC, and gastric cancer ex vivo. These findings were confirmed using a known antiFGFR2 antibody. We also provide evidence that peptide binding does not affect downstream cell signaling. This peptide can potentially be used for therapy by labeling nanocarriers to achieve site-specific drug delivery of high payloads [25]. These results justify further development of this peptide for clinical imaging in patients at high risk for epithelial-derived cancers in the esophagus and stomach.

Peptides are being developed for early detection of Barrett's neoplasia. Wide-field fluorescence imaging techniques have been demonstrated that rapidly visualize large mucosal surfaces to provide a "red flag" region to identify high risk areas and guide tissue resection [20]. We have previously identified a 7 amino acid peptide ASYNYDA that was labeled with FITC [19]. This sequence was selected using phage display in an unbiased screen against human H460 adenocarcinoma cells found later to be lung rather than esophageal in origin, [26] and the protein target was not definitively determined. We have also identified peptides specific for EGFR and ErbB2.

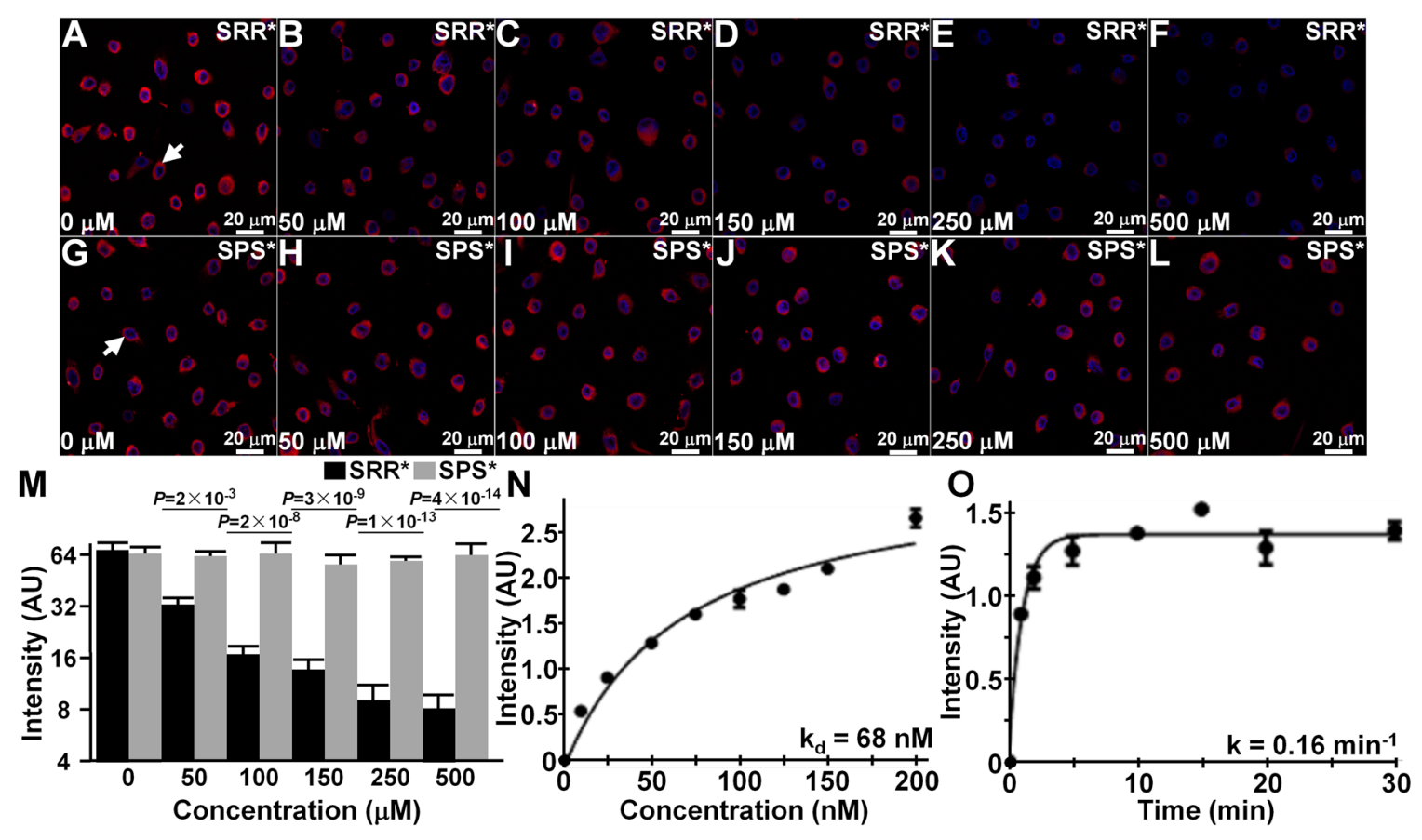

Figure 3: Characterization of specific FGFR2 peptide binding. (A-F) On competition with addition of unlabeled SRR* peptide at concentrations of $50 \mu \mathrm{M}$ and higher, we observed a significant decrease in binding of SRR ${ }^{*}$-Cy5.5 to QhTERT cells that express FGFR2c. (G-L) Non-significant differences were found with the addition of unlabeled SPS ${ }^{*}$. (M) Fluorescence intensities were fit to an ANOVA model with terms for 12 means. Signal was quantified from an average of 3 cells chosen randomly from 3 slides for each condition. $P$-values are shown above data, and compare differences in intensity with addition of unlabeled $\mathrm{SRR}^{*}$ and $\mathrm{SPS}^{*}$ at each concentration with the same difference with no unlabeled peptide. (N) Using flow cytometry, we measured an apparent dissociation constant of $\mathrm{k}_{\mathrm{d}}=68 \mathrm{nM}, \mathrm{R}^{2}=$ 0.96 , and $(\mathbf{O})$ an apparent association time constant of $\mathrm{k}=0.16 \mathrm{~min}^{-1}(6.2 \mathrm{~min})$ for binding of SRR ${ }^{*}$-Cy5.5 to QhTERT cells that express FGFR2c. These results are representative of 3 independent experiments. 

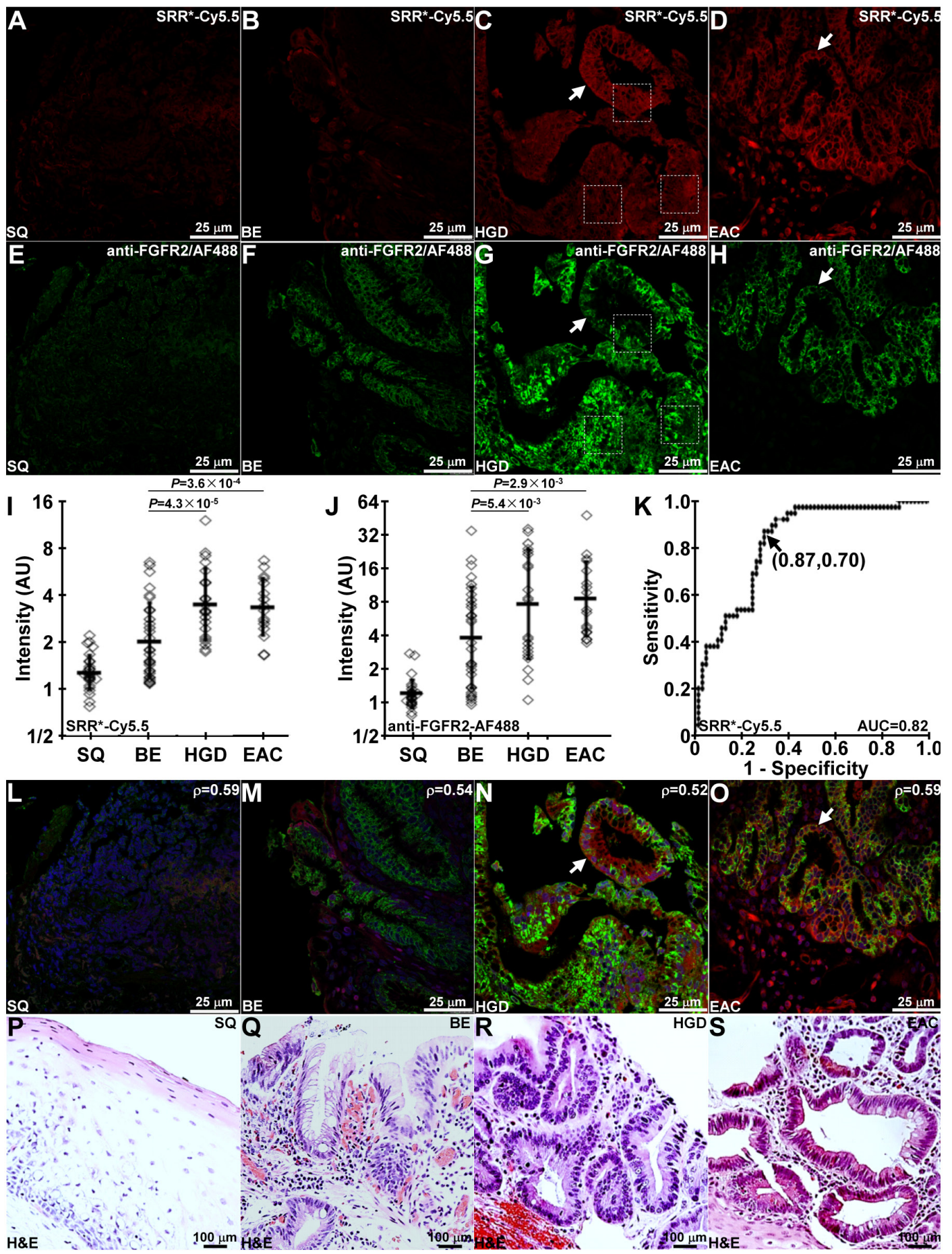

Figure 4: Binding of FGFR2 peptide to Barrett's neoplasia. On representative images collected with confocal microscopy of human esophageal specimens ex vivo, SRR ${ }^{*}$-Cy5.5 (red) shows minimal staining to (A) squamous (SQ) and (B) Barrett's esophagus (BE) and strong binding (arrows) to (C) high-grade dysplasia (HGD) and (D) esophageal adenocarcinoma (EAC). (E-H) Anti-FGFR2 antibody labeled with AF488 (green) was used as a positive control, and shows weak staining to SQ and BE but strong binding (arrows) to HGD and EAC. We quantified the fluorescence intensities from the mean of a set of 3 boxes with dimensions of $30 \times 30 \mu \mathrm{m}^{2}$ placed over cells, shown in panels $(\mathrm{C})$ and $(\mathrm{G})$. From $\mathrm{n}=28,33,22$, and 17 specimens of SQ, BE, HGD, and EAC, respectively, we found significantly greater mean fluorescence intensity from HGD and EAC compared with that for BE with (I) SRR*-Cy5.5 and (J) AF488-labeled anti-FGFR2 using an ANOVA model with terms for 4 means on log-transformed data. (K) ROC curve shows $87 \%$ sensitivity and $70 \%$ specificity for detecting Barrett's neoplasia (HGD and EAC) at a T/B ratio of 3.0. (L-O) Merged images shows co-localization of peptide (red) and antibody (green) binding. We determined a Pearson's correlation coefficient of $\rho=0.59,0.54,0.52$ and 0.59 for SQ, BE, HGD and EAC, respectively. Representative histology (H\&E) are shown for (P) SQ, (Q) BE, (R) HGD, and (S) EAC. 
$[27,28]$ These genes are frequently highly amplified in EAC [29]. A panel of targets may be needed to achieve acceptable performance for early detection of Barrett's neoplasia. [10] Peptides have similar binding onsets, and multiplexed detection has been demonstrated in vivo [21]. Previously, a peptide specific for FGFR2 was developed as a precursor for red luminescent gold nanoclusters [30]. This peptide binds to human esophageal SCC cells in vitro and produces good luminescence with high stability, nontoxicity and biocompatibility. Development for clinical imaging has not been performed.

New imaging strategies are needed for early detection of Barrett's neoplasia. Probes that target FGFR2, including antibodies, lectins, and small molecules, are being developed. GP369 is an antibody specific for FGFR2b that exhibits potent anti-tumor activity [31]. Antibodies have been repurposed for in vivo imaging, however widespread clinical use of this probe platform for diagnostics has been limited by slow binding kinetics, immunogenicity, and high production costs [32]. Lectins have been shown to target Barrett's neoplasia ex vivo [33]. However, these agents have low diversity and may not achieve sufficient binding affinity for in vivo use. Moreover, the glycoprotein targets are under expressed with progression of disease, thus produce a negative contrast that can be prone to false-positives in vivo. Tyrosine kinase inhibitors have been shown to decrease survival of gastric cancer cells with FGFR2 amplifications in vitro [34]. Other methods of wide-area endoscopy, including chromoendoscopy, [35] narrowband imaging (NBI), [36] and autofluorescence imaging (AFI), [37] have been evaluated clinically, but provide low intrinsic contrast and are based on non-specific mechanisms. In clinical studies, these approaches have not demonstrated a clear advantage over conventional white light endoscopy with random biopsies.

In addition to Barrett's neoplasia, FGFR2 is overexpressed in other epithelial-derived cancers, including esophageal SCC, [38] gastric, [39] esophagogastric junction, [40] colorectal, [41] pancreatic, [42] and breast [43]. We present immunofluorescence results to support broad use of this FGFR2 peptide for detection of esophageal SCC and gastric cancer, Supplementary Figures 5, 6. In Barrett's neoplasia, we found LGD and HGD to be more difficult to distinguish than esophageal SCC because BE has higher FGFR2 expression than normal squamous epithelium. For future clinical validation, we will use current Good Manufacturing Practices (cGMP) to synthesize the FGFR2 peptide for use in a rigorous animal pharmacology/

\section{A QhTERT/FGFR2b}

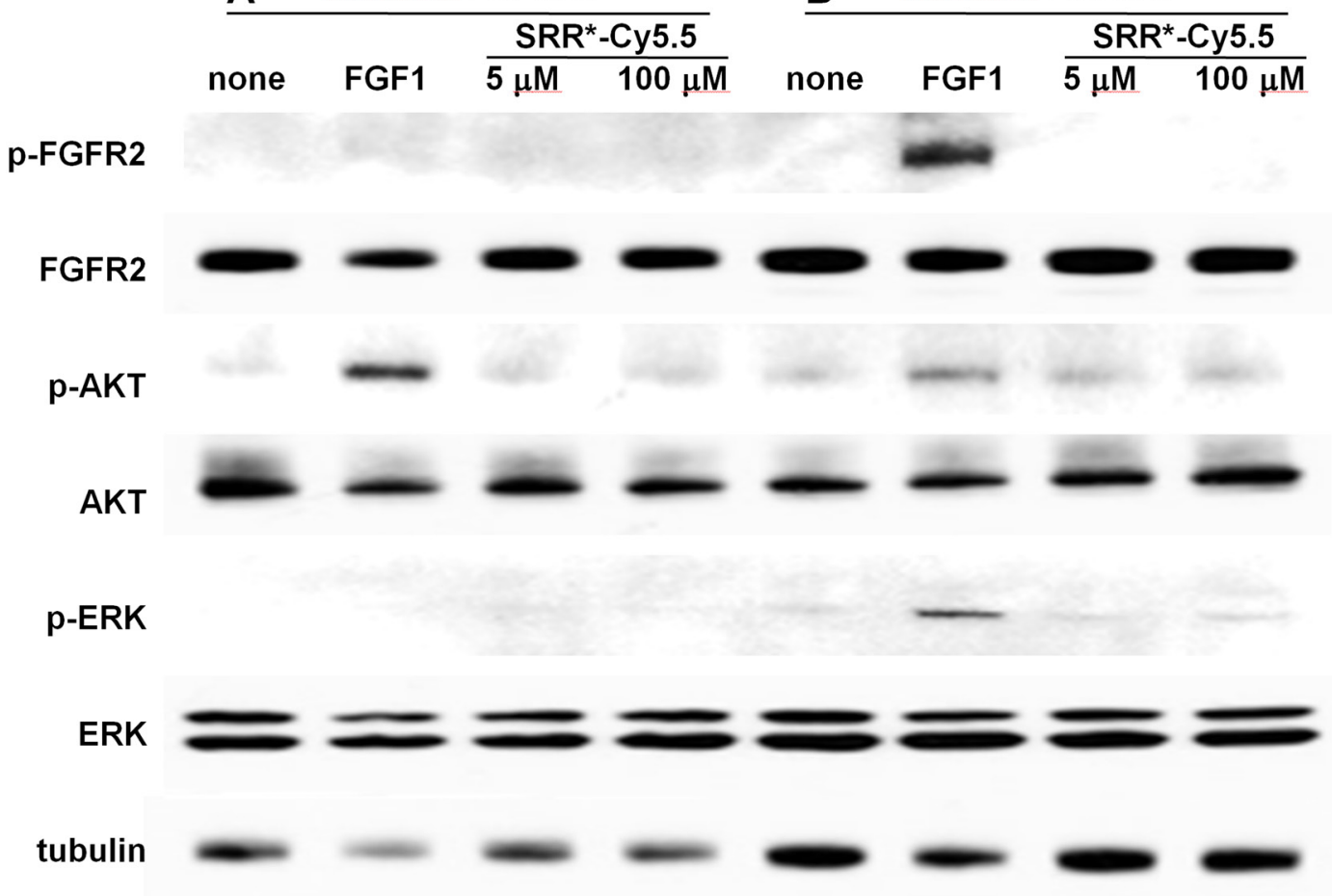

Figure 5: FGFR2 peptide does not affect cell signaling. Western blot shows no obvious change in phosphorylation for either FGFR2 (p-FGFR) or downstream AKT (p-AKT) and ERK (p-ERK) with addition of SRR* peptide at 5 and $100 \mu \mathrm{M}$ to QhTERT cells that express FGFR2b or FGFR2c compared with untreated cells. Addition of FGF1 as positive control to bind FGFR2b and FGFR2c shows phosphorylation activity for FGFR2 (p-FGFR), downstream AKT (p-AKT) and ERK (p-ERK), especially in QhTERT cells expressing FGFR2c. 
toxicology study to be performed with Good Laboratory Practices (GLP). This data will be included in an Investigational New Drug (IND) application submitted to the FDA for in vivo use in human subjects. Because the region of the distal esophagus affected by $\mathrm{BE}$ is only a few centimeters in length, the peptide can be administered topically rather than intravenously at a high concentration to maximize target interactions and achieve rapid binding with minimal risk for toxicity [20]. In conclusion, expression of FGFR2 is an early event in progression from $\mathrm{BE}$ to EAC. We have identified and validated a peptide specific for this cell surface target for future clinical use in early detection of EAC. This strategy may be applied to imaging of other epithelial-derived cancers.

\section{MATERIALS AND METHODS}

\section{Tissues, cells, and chemicals}

All human esophageal specimens were obtained with written, informed patient consent per approval and guidelines of the University of Michigan Institutional Review Board (IRB). Human non-dysplastic Barrett's esophagus (BE) cells immortalized with hTert (QhTERT) were obtained from the American Type Culture Collection (ATCC) and cultured in keratinocyte-serum free medium containing bovine pituitary extract and human recombinant EGF (ThermoFisher \#17005042). QhTERT cells with stable expression of FGFR2b or FGFR2c were provided (DGB) [44]. We cultured these cells with keratinocyteserum free medium containing bovine pituitary extract and human recombinant EGF (ThermoFisher \#17005042) and added $1 \mu \mathrm{g} / \mathrm{mL}$ of puromycin-dihydrochloride (Invitrogen \#A11138-03). All cells were cultured at $37^{\circ} \mathrm{C}$ in $5 \% \mathrm{CO}_{2}$, and were passaged using $0.25 \%$ EDTA containing trypsin (Mediatech Inc). A hemocytometer was used to determine cell number. Peptide synthesis reagents were obtained from either Anaspec or AAPPTEC with the highest grade available ( $>99 \%$ purity) and used without further purification. Solvents and other chemical reagents were obtained from Sigma-Aldrich, unless otherwise stated.

\section{Selection of peptide specific for FGFR2}

We performed peptide selection using the extracellular domain (ECD) of FGFR2c. This region of the target is accessible to imaging. We obtained recombinant FGFR2-ECD (Met1-Glu377) consisting of 367 amino acids after removal of the signal peptide (\#10824-H08H50, Sino Biological). We performed SDS-PAGE with $1 \mu \mathrm{g}$ of FGFR2-ECD to evaluate the quality and quantity using $0.25,0.5$, and $1 \mu \mathrm{g}$ of BSA as control. Peptide selection was performed using a phage display library (New England Biolabs, Ph.D.-12) per manufacturer instructions. This library consists of M13 bacteriophage that expresses $\sim 10^{9}$ unique 12 -amino acid sequences. $2 \times 10^{11}$ pfu consisting of $2 \times 10^{9}$ unique clones with $\sim 100$ copies each were biopanned against FGFR2-ECD immobilized in a 6-well plate at $4^{\circ} \mathrm{C} .4$ rounds of biopanning were performed using a decreasing quantity $(100,80,60$, and $40 \mu \mathrm{g})$ of FGFR2ECD in successive rounds to increase binding specificity. After the 4th round, 50 plaques were randomly selected for DNA preparation and sequence analysis. We used an ABI Automatic DNA Analyzer (Applied Biosystems) with primer 5'-CCCTCATAG TTA GCG TAA CG-3' (-96 gIII sequencing primer, New England Biolabs) that corresponds to the pIII gene sequence of the M13 phage.

\section{Synthesis of peptide specific for FGFR2}

We used standard Fmoc-mediated solid-phase synthesis to produce the Cy5.5-labeled peptides [45]. We assembled Fmoc and Boc protected $L$-amino acids on rink amide MBHA resin. The peptides were synthesized using a PS3 automatic synthesizer (Protein Technologies Inc). The C-terminal lysine was incorporated as FmocLys (ivDde)-OH, and the N-terminal amino acid was incorporated with Boc protection to avoid unwanted Fmoc removal during deprotection of the ivDde moiety prior to fluorophore labeling. Upon complete assembly of the peptide, the resin was transferred to a reaction vessel for manual labeling with dye. The ivDde side chain protecting group was removed with 5\% hydrazine in DMF $(3 \times 10 \mathrm{~min})$ with continuous shaking at room temperature (RT). The resin was washed with dimethylformamide (DMF) and dichloromethane (DCM) 3X each for 1 min. The protected resin-bound peptide was incubated overnight with Cy5.5-NHS ester (Lumiprobe LLC) with DIEA, and the completion of the reaction was monitored by a qualitative Ninhydrin test. Upon completion of labeling, the peptide was cleaved from the resin using TFA:TIS:H2O (95:2.5:2.5 v/v/v; Sigma-Aldrich) for 4 hours with shaking in the dark at RT. After separating the peptide from the resin, the filtrate was evaporated with $\mathrm{N}_{2}$ gas followed by precipitation with chilled diethyl ether and stored overnight at $-20^{\circ} \mathrm{C}$. The precipitate was centrifuged at $3000 \mathrm{rpm}$ for $5 \mathrm{~min}$ and washed with diethyl ether $3 \mathrm{X}$ and centrifuged in between each washing step. The crude peptides were dissolved in 1:1 acetonitrile/H2O (v/v) and purified by prep-HPLC with a $\mathrm{C}_{18}$ column (Waters Inc) using a water ( $0.1 \%$ TFA)-acetonitrile $(0.1 \%$ TFA) gradient. The final purity of the peptides was confirmed with an analytical $\mathrm{C}_{18}$-column. Further characterization was performed with either ESI (Waters Inc) or Q-TOF (Agilent Technologies) mass spectrometry.

\section{Confocal fluorescence microscopy}

$\sim 10^{3} \quad$ QhTERT/wt, QhTERT/FGFR2b, and QhTERT/FGFR2c cells were grown on cover glass to $\sim 80 \%$ confluence. The cells were washed with PBS $1 \mathrm{X}$ and incubated with $1 \mu \mathrm{M}$ of either peptide for $10 \mathrm{~min}$ at 
RT. The cells were then washed $3 \mathrm{X}$ in PBS, fixed with $4 \%$ paraformaldehyde (PFA) for $5 \mathrm{~min}$, washed $1 \mathrm{X}$ with PBS, and then mounted on glass slides with ProLong Gold reagent containing DAPI (Invitrogen). Confocal fluorescence images were collected with Cy5.5 and DAPI filters (Leica Inverted SP5X 2-Photon FLIM confocal microscopes) using a $63 \mathrm{X}$ oil-immersion objective. Fluorescence intensities from 3 cells in each of 3 independent images were quantified using custom Matlab (Mathworks) software.

\section{Competition for peptide binding}

Specific peptide binding to QhTERT/FGFR2c was validated on competitive inhibition with addition of unlabeled peptide. $\sim 10^{3}$ cells were grown to $\sim 70 \%$ confluence on cover glass in triplicate. Unlabeled peptides at concentrations of $0,50,100,150,250$, and $500 \mu \mathrm{M}$ were incubated with the cells for $30 \mathrm{~min}$ at $4^{\circ} \mathrm{C}$. The cells were washed and incubated with $5 \mu \mathrm{M}$ of the target peptide for another $30 \mathrm{~min}$ at $4{ }^{\circ} \mathrm{C}$. The cells were washed and fixed with 4\% PFA for $5 \mathrm{~min}$. The cells were washed with PBS and mounted with ProLong Gold reagent containing DAPI (Invitrogen).

\section{Characterization of peptide binding}

We measured the apparent dissociation constant $\mathrm{k}_{\mathrm{d}}$ for peptide binding to cells to assess binding affinity [46]. The Cy5.5-labeled peptide was serially diluted in PBS at concentrations ranging from 0 to $200 \mathrm{nM}$ in $25 \mathrm{nM}$ increments. QhTERT/FGFR2c cells $\left(\sim 10^{5}\right)$ were incubated with peptide at $4^{\circ} \mathrm{C}$ for 1 hour, washed with cold PBS, and the mean fluorescence intensities were measured using flow cytometry. The equilibrium dissociation constant $\mathrm{k}_{\mathrm{d}}=1 / \mathrm{k}_{\mathrm{a}}$ was calculated by performing a least squares fit of the data to the non-linear equation $\mathrm{I}=\left(\mathrm{I}_{0}+\mathrm{I}_{\max } \mathrm{k}_{\mathrm{a}}[\mathrm{X}]\right) /$ $\left(\mathrm{I}_{0}+\mathrm{k}_{\mathrm{a}}[\mathrm{X}]\right) . \mathrm{I}_{0}$ and $\mathrm{I}_{\max }$ are the initial and maximum fluorescence intensities, corresponding to no peptide and at saturation, respectively, and $[\mathrm{X}]$ represents the concentration of the bound peptide. Prism 5.0 software (GraphPad Inc) was used to calculate $\mathrm{k}_{\mathrm{d}}$.

We measured the apparent association time constant of the peptide to QhTERT/FGFR2c cells to assess binding onset [47]. Cells were grown to $\sim 80 \%$ confluence in 10 $\mathrm{cm}$ dishes, and detached with PBS-based cell dissociation buffer (Invitrogen). Cells ( $\sim 10^{5}$ were incubated with 5 $\mu \mathrm{M}$ SRR-Cy5.5 at RT for various time intervals ranging from 0 to $30 \mathrm{~min}$. The cells were centrifuged, and washed with cold PBS. Flow cytometry analysis was performed as described above, and the median fluorescence intensity (y) were measured on flow cytometry at different time points ( $\mathrm{t}$ ) using Flowjo software. The rate constant $\mathrm{k}$ was calculated by fitting the data to a first order kinetics model, $\mathrm{y}(\mathrm{t})=\mathrm{I}_{\max }\left[1-\exp ^{(-\mathrm{kt})}\right]$, where $\mathrm{I}_{\max }=$ maximum value using Prism 5.0 software (GraphPad Inc).

\section{Binding of FGFR2 peptide and antibody to human esophageal specimens}

Formalin-fixed sections of human esophageal specimens were deparaffinized, and antigen retrieval was performed using standard methods. Briefly, the sections were incubated in xylene for 3 min $3 \mathrm{X}$, washed with 100\% ethanol for $2 \min 2 X$, and washed with $95 \%$ ethanol for 2 min $2 \mathrm{X}$. Rehydration was performed by washing in $\mathrm{dH}_{2} \mathrm{O}$ for 5 min $2 \mathrm{X}$. Antigen unmasking was performed by boiling the slides in $10 \mathrm{mM}$ sodium citrate buffer with $0.05 \%$ Tween at $\mathrm{pH} 6.0$, and then maintaining at subboiling temperature for $15 \mathrm{~min}$. The slides were cooled for $30 \mathrm{~min}$, and the sections were washed in $\mathrm{dH}_{2} \mathrm{O}$ for 3 min $3 \mathrm{X}$ and in PBS for $5 \mathrm{~min}$. Blocking was performed with DAKO protein blocking agent (X0909, DAKO) for 1 hour at RT. The peptides were incubated at a concentration of $1 \mu \mathrm{M}$ for $10 \mathrm{~min}$ at RT. The sections were washed in PBS for $3 \mathrm{~min} 3 \mathrm{X}$, and incubated with 1:1000 dilution of monoclonal anti-FGFR2 (Abcam, ab58201) overnight at $4^{\circ} \mathrm{C}$.

The sections were then washed in PBS for $5 \mathrm{~min}$ 3X. A 1:500 dilution of AF488-labeled secondary antibody (goat anti-mouse) was added to each section and incubated for $30 \mathrm{~min}$ at RT. The secondary antibody solution was removed by washing with PBS for $5 \mathrm{~min} 3 \mathrm{X}$. The sections were then mounted with ProLong Gold reagent containing DAPI (Invitrogen). The mean fluorescence intensities from 3 boxes (dimensions of $30 \times 30 \mu \mathrm{m}^{2}$ ) located completely within the surface epithelium of each specimen were measured. Regions that showed intensity saturation were avoided. Serial sections were processed for routine histology (H\&E), and were reviewed by an expert gastrointestinal pathologist (HDA).

\section{Effect of peptide on cell signaling}

QhTERT cells that overexpress either FGFR2b or FGFR2c were seeded in 12-well flat-bottom plates with $500 \mu \mathrm{L}$ of serum-free medium for 16 hours. FGF1 (\#2232-FA-025, R\&D systems) was reconstituted to a concentration of $100 \mu \mathrm{g} / \mathrm{mL}$ using PBS, diluted with $0.1 \%$ bovine serum albumin, and added to the cells at final concentrations of $100 \mathrm{ng} / \mathrm{mL}$ for $20 \mathrm{~min}$ in separate wells. Heparin (\# H3149-10KU, Sigma) with final concentration of 100 units $/ \mathrm{mL}$ was also added to increase stability. In addition, peptides at concentrations of 5 and $100 \mu \mathrm{M}$ were incubated for $20 \mathrm{~min}$ in separate wells. The cells were washed with PBS and lysed in RIPA buffer containing protease inhibitors (\#11836170001, Roche, Basel, Switzerland). Lysates were separated by gel electrophoresis, transferred to polyvinylidene difluoride membranes (\#ISEQ00010, Millipore), and detected by immunoblotting using an enhanced chemiluminescence system (\#RPN2106, GE Healthcare). Anti-FGFR2 antibody (\#SC122, Santa Cruz Biotechnology), anti- 
phospho-FGFR (\#3471, Cell Signaling Technology), antiAKT (\#4691P, Cell Signaling Technology), anti-ERK1/2 (\#4695P, Cell Signaling Technology), anti-phosphoAKT (pS473; \#4060P, Cell Signaling Technology), antiphospho-ERK1/2 (\#4370P, Cell Signaling Technology), and anti-tubulin (\#32-2600, Invitrogen) were used as per manufacturer's instructions.

\section{Abbreviations}

BE - Barrett's esophagus; EAC - esophageal adenocarcinoma; EMR - endoscopic mucosal resection; FGFR - fibroblast growth factor receptor; HGD - highgrade dysplasia; IF - immunofluorescence; IHC immunohistochemistry; LGD - low-grade dysplasia; NIR - near-infrared; ROI - regions of interest; RFA radio-frequency ablation; RT - room temperature; RTK - receptor tyrosine kinase; SQ - squamous; T/B - targetto-background.

\section{Author contributions}

Designed research - JZ, ML, TDW.

Performed research - JZ, LH, ZP, ML, TDW.

Contributed new reagents or analytic tools $-\mathrm{JZ}$, TDW.

Analyzed data - JZ, HDA, RK, DGB, ML, TDW. Wrote manuscript - JZ, RK, TDW.

\section{CONFLICTS OF INTEREST}

The authors declare no conflicts of interest.

\section{FUNDING}

Funding provided in part by National Institutes of Health U54 CA163059, U01 CA189291 (TDW, DGB) and the University of Michigan Cancer Center Support Grant (P30 CA046592).

\section{REFERENCES}

1. Torre LA, Siegel RL, Ward EM, Jemal A. Global cancer incidence and mortality rates and trends - an update. Cancer Epidemiol Biomarkers Prev. 2016; 25:16-27.

2. Hur C, Miller M, Kong CY, Dowling EC, Nattinger KJ, Dunn M, Feuer EJ. Trends in esophageal adenocarcinoma incidence and mortality. Cancer. 2013; 119:1149-58.

3. Whiteman DC, Sadeghi S, Pandeya N, Smithers BM, Gotley DC, Bain CJ, Webb PM, Green AC; Australian Cancer Study. Combined effects of obesity, acid reflux and smoking on the risk of adenocarcinomas of the oesophagus. Gut. 2008; 57:173-80.

4. Odze RD. Diagnosis and grading of dysplasia in Barrett's oesophagus. J Clin Pathol. 2006; 59:1029-38.
5. Curvers WL, ten Kate FJ, Krishnadath KK, Visser M, Elzer B, Baak LC, Bohmer C, Mallant-Hent RC, van Oijen A, Naber AH, Scholten P, Busch OR, Blaauwgeers $\mathrm{HG}$, et al. Low-grade dysplasia in Barrett's esophagus: overdiagnosed and underestimated. Am J Gastroenterol. 2010; 105:1523-30.

6. Wang KK, Sampliner RE; Practice Parameters Committee of the American College of Gastroenterology. Updated guidelines 2008 for the diagnosis, surveillance and therapy of Barrett's esophagus. Am J Gastroenterol. 2008; 103:788-97.

7. Sharma P, Savides TJ, Canto MI, Corley DA, Falk GW, Goldblum JR, Wang KK, Wallace MB, Wolfsen HC; ASGE Technology and Standards of Practice Committee. The American Society for Gastrointestinal Endoscopy PIVI (Preservation and Incorporation of Valuable Endoscopic Innovations) on imaging in Barrett's Esophagus. Gastrointest Endosc. 2012; 76:252-4.

8. Sturm MB, Wang TD. Emerging optical methods for surveillance of Barrett's oesophagus. Gut. 2015; 64:1816-23.

9. Sergina NV, Rausch M, Wang D, Blair J, Hann B, Shokat KM, Moasser MM. Escape from HER-family tyrosine kinase inhibitor therapy by the kinase-inactive HER3. Nature. 2007; 445:437-41.

10. Paterson AL, O'Donovan M, Provenzano E, Murray LJ, Coleman HG, Johnson BT, McManus DT, Novelli M, Lovat LB, Fitzgerald RC. Characterization of the timing and prevalence of receptor tyrosine kinase expression changes in oesophageal carcinogenesis. J Pathol. 2013; 230:118-28.

11. Ornitz DM, Itoh N. The Fibroblast Growth Factor signaling pathway. Wiley Interdiscip Rev Dev Biol. 2015; 4:215-66.

12. Ibrahimi OA, Eliseenkova AV, Plotnikov AN, Yu K, Ornitz DM, Mohammadi M. Structural basis for fibroblast growth factor receptor 2 activation in Apert syndrome. Proc Natl Acad Sci U S A. 2001; 98:7182-7.

13. Orr-Urtreger A, Bedford MT, Burakova T, Arman E, Zimmer Y, Yayon A, Givol D, Lonai P. Developmental localization of the splicing alternatives of fibroblast growth factor receptor-2 (FGFR2). Dev Biol. 1993; 158:475-86.

14. Eswarakumar VP, Lax I, Schlessinger J. Cellular signaling by fibroblast growth factor receptors. Cytokine Growth Factor Rev. 2005; 16:139-49.

15. Fletcher MN, Castro MA, Wang X, de Santiago I, O'Reilly M, Chin SF, Rueda OM, Caldas C, Ponder BA, Markowetz F, Meyer KB. Master regulators of FGFR2 signalling and breast cancer risk. Nat Commun. 2013; 4:2464.

16. Dufour C, Guenou H, Kaabeche K, Bouvard D, Sanjay A, Marie PJ. FGFR2-Cbl interaction in lipid rafts triggers attenuation of PI3K/Akt signaling and osteoblast survival. Bone. 2008; 42:1032-9.

17. Fang X, Yang D, Luo H, Wu S, Dong W, Xiao J, Yuan S, Ni A, Zhang KJ, Liu XY, Chu L. SNORD126 promotes HCC and CRC cell growth by activating the PI3K-AKT pathway through FGFR2. J Mol Cell Biol. 2017; 9: 243-55. 
18. Nomura S, Yoshitomi H, Takano S, Shida T, Kobayashi S, Ohtsuka M, Kimura F, Shimizu H, Yoshidome H, Kato A, Miyazaki M. FGF10/FGFR2 signal induces cell migration and invasion in pancreatic cancer. Br $\mathrm{J}$ Cancer. 2008; 99:305-13.

19. Sturm MB, Joshi BP, Lu S, Piraka C, Khondee S, Elmunzer BJ, Kwon RS, Beer DG, Appelman HD, Turgeon DK, Wang TD. Targeted imaging of esophageal neoplasia with a fluorescently labeled peptide: first-in-human results. Sci Transl Med. 2013; 5:184ra61.

20. Joshi BP, Duan X, Kwon RS, Piraka C, Elmunzer BJ, Lu S, Rabinsky EF, Beer DG, Appelman HD, Owens SR, Kuick R, Doguchi N, Turgeon DK, Wang TD. Multimodal endoscope can quantify wide-field fluorescence detection of Barrett's neoplasia. Endoscopy. 2016; 48:A1-13.

21. Joshi BP, Miller SJ, Lee CM, Seibel EJ, Wang TD. Multispectral endoscopic imaging of colorectal dysplasia in vivo. Gastroenterology. 2012; 143:1435-7.

22. Sturm MB, Piraka C, Elmunzer BJ, Kwon RS, Joshi BP, Appelman HD, Turgeon DK, Wang TD. In vivo molecular imaging of Barrett's esophagus with confocal laser endomicroscopy. Gastroenterology. 2013; 145:56-8.

23. Luo S, Zhang E, Su Y, Cheng T, Shi C. A review of NIR dyes in cancer targeting and imaging. Biomaterials. 2011; 32:7127-38.

24. Plotnikov AN, Hubbard SR, Schlessinger J, Mohammadi M. Crystal structures of two FGF-FGFR complexes reveal the determinants of ligand-receptor specificity. Cell. 2000; 101:413-24.

25. Khondee S, Rabinsky EF, Owens SR, Joshi BP, Qiu Z, Duan X, Zhao L, Wang TD. Targeted therapy of colorectal neoplasia with rapamycin encapsulated in peptide-labeled pegylated octadecyl lithocholate micelles. J Control Release. 2015; 199:114-21.

26. Boonstra JJ, van Marion R, Beer DG, Lin L, Chaves P, Ribeiro C, Pereira AD, Roque L, Darnton SJ, Altorki NK, Schrump DS, Klimstra DS, Tang LH, et al. Verification and unmasking of widely used human esophageal adenocarcinoma cell lines. J Natl Cancer Inst. 2010; 102:271-4.

27. Zhou J, Joshi BP, Duan X, Pant A, Qiu Z, Kuick R, Owens SR, Wang TD. EGFR overexpressed in colonic neoplasia can be detected on wide-field endoscopic imaging. Clin Transl Gastroenterol. 2015; 6:e101.

28. Joshi BP, Zhou J, Pant A, Duan X, Zhou Q, Kuick R, Owens SR, Appelman H, Wang TD. Design and synthesis of nearinfrared peptide for in vivo molecular imaging of HER2. Bioconjug Chem. 2016; 27:481-94.

29. Dulak AM, Stojanov P, Peng S, Lawrence MS, Fox C, Stewart C, Bandla S, Imamura Y, Schumacher SE, Shefler E, McKenna A, Carter SL, Cibulskis K, et al. Exome and whole-genome sequencing of esophageal adenocarcinoma identifies recurrent driver events and mutational complexity. Nat Genet. 2013; 45:478-86.
30. Bi F, Yin H, Zheng S, Zhu Q, Yang H, Kang M, Gan F, Chen X. One-step synthesis of peptide conjugated gold nanoclusters for the high expression of FGFR2 tumor targeting and imaging. RSC Adv. 2016; 6:4627-33.

31. Bai A, Meetze K, Vo NY, Kollipara S, Mazsa EK, Winston WM, Weiler S, Poling LL, Chen T, Ismail NS, Jiang J, Lerner L, Gyuris J, Weng Z. GP369, an FGFR2-IIIb-specific antibody, exhibits potent antitumor activity against human cancers driven by activated FGFR2 signaling. Cancer Res. 2010; 70:7630-9.

32. Wu AM, Senter PD. Arming antibodies: prospects and challenges for immunoconjugates. Nat Biotechnol. 2005; 23:1137-46.

33. Bird-Lieberman EL, Neves AA, Lao-Sirieix P, O'Donovan M, Novelli M, Lovat LB, Eng WS, Mahal LK, Brindle KM, Fitzgerald RC. Molecular imaging using fluorescent lectins permits rapid endoscopic identification of dysplasia in Barrett's esophagus. Nat Med. 2012; 18:315-21.

34. Kim ST, Jang HL, Lee SJ, Lee J, Choi YL, Kim KM, Cho J, Park SH, Park YS, Lim HY, Yashiro M, Kang WK, Park JO. Pazopanib, a novel multitargeted kinase inhibitor, shows potent in vitro antitumor activity in gastric cancer cell lines with FGFR2 amplification. Mol Cancer Ther. 2014; 13:2527-36.

35. Ngamruengphong S, Sharma VK, Das A. Diagnostic yield of methylene blue chromoendoscopy for detecting specialized intestinal metaplasia and dysplasia in Barrett's esophagus: a meta-analysis. Gastrointest Endosc. 2009; 69:1021-8.

36. Mannath J, Subramanian V, Hawkey CJ, Ragunath K. Narrow band imaging for characterization of high grade dysplasia and specialized intestinal metaplasia in Barrett's esophagus: a meta-analysis. Endoscopy. 2010; 42:351-9.

37. Giacchino M, Bansal A, Kim RE, Singh V, Hall SB, Singh M, Rastogi A, Moloney B, Wani SB, Gaddam S, Mathur SC, Wallace MB, Kanakadandi V, et al. Clinical utility and interobserver agreement of autofluorescence imaging and magnification narrow-band imaging for the evaluation of Barrett's esophagus: a prospective tandem study. Gastrointest Endosc. 2013; 77:711-8.

38. Kato H, Arao T, Matsumoto K, Fujita Y, Kimura H, Hayashi H, Nishiki K, Iwama M, Shiraishi O, Yasuda A, Shinkai M, Imano M, Imamoto $\mathrm{H}$, et al. Gene amplification of EGFR, HER2, FGFR2 and MET in esophageal squamous cell carcinoma. Int J Oncol. 2013; 42:1151-8.

39. Han N, Kim MA, Lee HS, Kim WH. Evaluation of fibroblast growth factor receptor 2 expression, heterogeneity and clinical significance in gastric cancer. Pathobiology. 2015; 82:269-79.

40. Tokunaga $\mathrm{R}$, Imamura $\mathrm{Y}$, Nakamura $\mathrm{K}$, Ishimoto $\mathrm{T}$, Nakagawa S, Miyake K, Nakaji Y, Tsuda Y, Iwatsuki M, Baba Y, Sakamoto Y, Miyamoto Y, Saeki H, et al. Fibroblast growth factor receptor 2 expression, but not its genetic amplification, is associated with tumor growth and worse survival in esophagogastric junction adenocarcinoma. 
Oncotarget. 2016; 7:19748-61. https://doi.org/10.18632/ oncotarget. 7782 .

41. Matsuda Y, Ueda J, Ishiwata T. Fibroblast growth factor receptor 2: expression, roles, and potential as a novel molecular target for colorectal cancer. Patholog Res Int. 2012; 2012:574768.

42. Matsuda Y, Yoshimura H, Suzuki T, Uchida E, Naito Z, Ishiwata $\mathrm{T}$. Inhibition of fibroblast growth factor receptor 2 attenuates proliferation and invasion of pancreatic cancer. Cancer Sci. 2014; 105:1212-9.

43. Lee HJ, Seo AN, Park SY, Kim JY, Park JY, Yu JH, Ahn JH, Gong G. Low prognostic implication of fibroblast growth factor family activation in triple-negative breast cancer subsets. Ann Surg Oncol. 2014; 21:1561-8.

44. Lin L, Bass AJ, Lockwood WW, Wang Z, Silvers AL, Thomas DG, Chang AC, Lin J, Orringer MB, Li W, Glover
TW, Giordano TJ, Lam WL, et al. Activation of GATA binding protein 6 (GATA6) sustains oncogenic lineagesurvival in esophageal adenocarcinoma. Proc Natl Acad Sci U S A. 2012; 109:4251-6.

45. Merrifield RB. Solid phase peptide synthesis. I. The synthesis of a tetrapeptide. J Am Chem Soc. 1963; $85: 2149-2154$.

46. Thomas R, Chen J, Roudier MM, Vessella RL, Lantry LE, Nunn AD. In vitro binding evaluation of $177 \mathrm{Lu}-\mathrm{AMBA}$, a novel 177Lu-labeled GRP-R agonist for systemic radiotherapy in human tissues. Clin Exp Metastasis. 2009; 26:105-19.

47. Joshi BP, Liu Z, Elahi SF, Appelman HD, Wang TD. Nearinfrared-labeled peptide multimer functions as phage-mimic for high affinity, specific targeting of colonic adenomas in vivo. Gastrointest Endosc. 2012; 76:1197-206. 